\title{
REMARKS ON THE BASIC PLAN OF THE TERMINAL ABDOMINAL STRUCTURES OF THE MALES OF WINGED INSECTS.
}

BY G. C. CRAMPTON, PH. D.

Massachusetts Agricultural College, Amherst, Mass.

The genitalia of male Hymenoptera, Neuroptera, Mecoptera, Diptera, Trichoptera, Lepidoptera, Hemiptera (Homoptera) and Strepsiptera have been compared with those of the lower orders in a paper which appeared in "Psyche," (June, 1920). The added knowledge gained from this study of a wider range of forms, and from an examination of the condition occurring in arthropods related to insects, together with the light thrown upon the nature of the parts in the lower insects in Dr. Walker's recent description of the genitalia of the male of Grylloblatta campodeiformis (Can. Ent., LI, 1919, p. 131) have enabled me to come to a better understanding of the fundanental composition of the terminal structures of the Hexapoda, and the following suggestions are here offered in an effort to clear up some of the uncertainties concerning the interpretation of the parts in insects in general and in the higher forms in particular.

Embryologists have maintained that the abdomen of an insect is primarily composed of twelve segments-mor eleven segments, with a "telson"--and since the abdomen of the Protura (which atre among the most primitive representatives of the Hexapoda) is composed of twelve segneuts, there is some evidence for considering that twelve is the original number of segments entering in to the composition of the abdominal region of insects in general. It is only in exceptional cases, however, that traces of the structures interpreted as the vestiges of a twelfth segment are retained (as in certain odonatan nymphs), and the retention of even eleven complete segments is by no means of common occurrence in the lower pterygotan orders, since the eleventh tergite (" $11^{\text {t" }}$ of Fig. 5) is usually lost through atrophy of fusion with the preceding tergites, though certain latero-ventral parts of the eleventh segment are frequently retained to form the so-called paraprocts "e" (Figs. 1 and 5) of lower insects.

The paraprocts "e" (Figs. 1 and 5) are usually much reduced, and unite with the tergites of the tenth or other segments to form the anal papilla or proctiger (a structure bearing the anus) in higher forms (Fig. 6, "h"). The paraprocts, "e", are represented as though distinct, in the diagram of the parts of a sawfly shown in Fig. 3; but this does not correspond to the actual condition occurring in any known sawfly, since the paraprocts in these insects usually form the floor (and sides) of the anus-bearing structure whose tergal region is made up largely of the tenth tergite-which usually unites more or less closely with the ninth tergite in the sawfly group.

The cerci, "f", borne on the paraprocts "e" (Figs. 1, 3 and 5) are homologous with the multiarticulate flagelliform uropods of such Crustacea as the Tanaidacea (Chelifera). The exopodite, or outer branch of the biramous appendage forming the uropod, is sometimes wanting in these flagelliform uropods of the Tanaidacea, thus suggesting that when only one of the branches is retained, the endopodite, or inner one, remains to form the cerci of insects. When both branches of the uropod are retained in the Tanaidacea, they are borne upon a single segment or protopodite (if one may judge from the published figures of these structures, and from the condition exhibited by Apseudes spinosus) and on this account I have been led to conclude that Walker, 1919 (Ann. Ent. Soc. August, 1920. 
America, XII, 1919, p. 267) is incorrect in adopting the method of designating the basal segment of the cerci as the "basipodite," proposed by the German entomologists. Furthermore, it is quite possible that the paraprocts themselves (or a portion of them) represent the basal region of the uropod (see Fig. 5 , "e"), whose endopodite is represented by the cerci. If this be correct, we might also consider the styli-like "paraprocessi", or articulated processes borne on the paraprocts of certain tridactylids, as the representatives of the exopodite of the uropod whose endopodite forms the cerci of these insects.

The styli of insects apparently represent the exopodites of abdominal limbs, and if the paraprocessi also represent the exopodites of abdominal limbs (uropods) we would naturally expect that those paraprocessi would have the form of styli--as is true of the jointed paraprocessi of the tridactylids. On the other hand, the paraprocessi of certain Plecoptera are not styli-like, and the so-called suprahami (or surhami) of certain Blattida, which are somewhat suggestive of them, are not styli-like, being more like a hook-but the type of structure occurring in the Plecoptera might possibly be regarded as modifications of the original styli-like form. It may be remarked, in passing, that in some larva these styli have been interpreted as "cerci"; but this matter will be discussed eslewhwere.

The tenth tergite, "10", of Figs. 1 and 5 , has been referred to as the "epiproct," or supraanal plate, when it is sufficiently well developel to be distinguishable, although the same term has also been applied to the eleventh tergite " $11^{t "}$ in some cases. This is a somewhat lax application of the term epiproct, and Walker, 1919 (1.c.) is much more exact in restricting the designation epiproct or supraanal plate to the eleventh tergite. There is, however, an apparent need for some general designation for the last visible tergite no matter to what segment it belongs, and on this account I have here followed the more lax usage of referring to the apparent terminal tergite as the "epiproct" regardless of the segments involved in its make-up. In the sawflies, the tenth

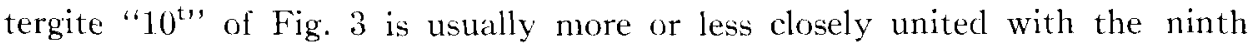
tergite, and in most higher insects it is difficult to identity its homologue. The sternum of the tenth segment is usually greatly reduced or atrophied, although it is claimed by some entomologists that the basal portion of the genital forceps "a" of Fig. 2, represents the tenth sternite in sawflies, etc. I think, however, that it is possible to interpret the structure in question in another way, as will be presently discussed. Heymons and others have maintained that lateral structures of the tenth segment form what appear to be the cerci in male Odonata, and there are sometimes present in certain phasmids, accessory lateral clasping organs which might be mistaken for cerci, though in reality they are merely posterior prolongations of the lateral region of the tergite.

Lateral portions of the ninth tergite may become prolonged posteriorly to form the surgonopods ("i" of Fig. 6) or accessory clasping organs of certain Neuroptera, Diptera and related forms, and have, in some cases, been mistaken for the true genital forceps when the latter are reduced and the surgonopods are well developed. The pleural region of the ninth segment labeled " 9 " " $\mathrm{ju}_{1}$ Fig. 6, has been homologized with the paraprocts "e" (Figs. 1, 3, 5, etc.) in

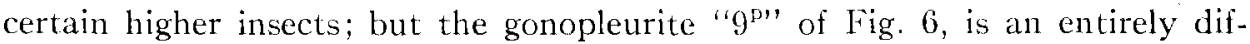
ferent structure, and should be designated by a term indicating this fact. The 
sternite of the ninth segment is a structure of considerable interest from the fact that in the higher orders it forms the hypandrium " $g$ " (Fig. 3) or ventral plate extending below the genital apparatus of the male insect, and its form and development offer features of some value in classification.

Behind the ninth sternite, or hypandrium " 9 " (Figs. 4 and 5 ) of the Ephemerida, there occurs a plate formed by the union of the "coxites" or styligers "a" and "a," which represent the basal segments of the gonopods or styli bearing the labels "b" and "c." The plate " $a$ " and "a" of Fig. 4 is usually interpreted as the tenth sternite by students of the Ephemerida (Morgan, Eaton, et al.); but Handlirsch, 1913, (Handb. der Entomologie) figures the terminal structures of a male ephemerid Palingenia, in which the styligers of "coxites" (i. e., the parts labeled " $a$ " in Fig. 4) are separate and distinct, and Walker, 1919 (1. c.) also points out that these "coxites" or styligers may unite to form the plate "a" and "a" hehind the ninth sternite in the Ephemerida (Fig. 4). This interpretation is apparently the correct one, and has been adopted in the present discussion.

Between the styli or gonopods labeled "b" and "c" in Figs. 4 and 5 of the Ephemerida, there occurs a pair of penisvalva "d," through which the ejaculatory ducts open. In some insects, the common opening of the united ducts is located at or near the base of the penis valves. It is quite possible that the penis valves "d" represent the endopodites (inner branches) of a pair of abdominal limbs whose exopodites (or outer branches) are represented by the styli or gonopods labeled "b" and "c" in Figs. 2, 3, 4, etc. If this be correct, both the penis valves and the gonopods would have to be regarded as belonging to the same segment (the ninth) since they are parts of a pair of limbs borne on one segment. This interpretation has a direct bearing on the view that the inner and the dorsal valvula of the ovipositor of the female also represent the endopodites and exopodites of a pair of abdominal limbs, since it is quite possible that the penis valves of the male insect are homologous with the inner valvulic of the ovipositor of the female; and the gonopods or styli of the male are homologous with the dorsal valvulix of the ovipositor of the female insect. The penis valves of the male and the inner valvule of the ovipositor of the female would represent cndopodites, while the styli (or gonopods) of the male and the dorsal valvulx of the ovipositor of the female would represent exopodites of a pair of abdominal limbs borne on the ninth segment in both cases, according to this view; but Wheeler, 1893, (Jour. Morphol., VIII, p. 1) maintains that the inner valvula of the ovipositor, for example, are in reality styli originally borne on the tenth sternite, and are only secondarily located on the ninth sternite as the result of their migration to their final position between the dorsal valvulæ (of the ovipositor) which are located on the ninth sternite. If this be correct, the inner valvula of the ovipositor (and their supposed homologues, the penis valves of the male) do not originate on the same segment with the dorsal valvulae of the ovipositor (or their supposed homologues, the gonopods or styli of the male), and therefore cannot be regarded as the endopodites of a pair of limbs whose exopodites are represented by the dorsal valvula (since the two branches of a biramous limb cannot originate on separate segments).

Wheeler, 1893, (l.c.) would interpret the three pairs of valvulee composing the ovipositor of a female insect, as three pairs of modified styliform appendages 
originally borne on the eighth, ninth and tenth sternites respectively, and homologizes them with paired styli borne on the eighth, ninth and tenth sternites of the malc While all three pairs of styli persist in the female (the pair originally borne on the tenth sternite migrating to a position on the ninth, in the fcmale), only the pair borne on the ninth sternite persist in the male, the other pairs gradually disappearing as development procecds. It must be admitted that Wheeler's choice of Xiphidium was an extremely unfortunate one, since the genitalia of the males of these insects are too highly modified to give the best results for such an investigation; and until the ontogenetic develop* ment of morc favorable forms, such as the Ephenerida, sawflies, etc., have becn studied with a view to determining the interpretation of the parts in male insects, we must conclude: that the evidence available is not entirely satisfactory, especially since Heymons, Palmen, and others who have also traced the development of the parts in males of lower insects, do not agree with Wheeler in many particulars.

A study of the so-ralled gonopods, or arthrostyles,* borne on the ninth abdominal segment in trichopterous larva, has convinced me that these structures form the claspers or gonopods of adult male caddice-filies (i. e., the structures labeled "c" and "b" in Fig. 2), and since these structurcs are evidently appendages of the ninth abdominal segment (not of the tenth abdominal segment, as was stated in the article published in Psyche) in caddice-fly larva, I would interpret the outer claspers of the genitalia of the males of higher insects as appendages (styli) of the ninth abdominal segment. On the other hand, the penis valves may or may not belong to the same segment, although $1 \mathrm{am}$ inclined to interpret them as appendages (endopodites ?) of the ninth abdominal segment also.

If the structures labeled "a" and " $b$ " in Fig. 1 are homologous with those labeled "a" and "b" (with "c") in Fig. .), and if thesc in turn are homologous with the structures labeled "a" and "b" (with "c") in Irig. 3, it is quite evident that there has been a considerable shifting of the parts in the different insects under consideration. Thus, in the roach shown in Fig. 1, the styligers or "coxites" labeled "a," instead of tending to remain more or less distinct as in the Ephemerida ("a" of Figs. 4 and 5), become more closely united with the ninth sternite " 9 " of Fig. 1, while the penis valves "d" are apparently attached behind the posterior border of the ninth sternite-which has either grown out posteriorly beneath them, or the penis valves have been shifted forward basally. If the structures bearing the label " $\mathrm{d}$ " in Fig. 1 are the homologues of the penis valves of the other insects figured, they have followed a line of specialization leading toward the asymmetrical development of the parts, and their relation to the styli or gonopods "a" and "b" is somewhat different from that occurring in the higher insects.

Another course of development has apparently been followed in the sawfly shown in Fig. 3, since the ninth sternite " 9 " (which does not project far posteriorly in the ephemerid shown in Fig. 5, "g") has grown outward and back-

*In the larra of certain sawflies such as Neurotoma, there occur near the base of the sternite of the tenth abdrminal segment, a pair of jointed appendages which I interpreted as segmented styli (arthrostyles) from the fact that they are borne on the starnum of the segment. Mr. Middleton, however, informs me that these apparent arthrostyles are transformed into the cerci of the adult male insect, and if this be correct, the structures in question should be designated as cerci rather than as styli (or arthrostyles) in these larvx. 
CAN, Ent., Vol. LII.

Plate Vi.
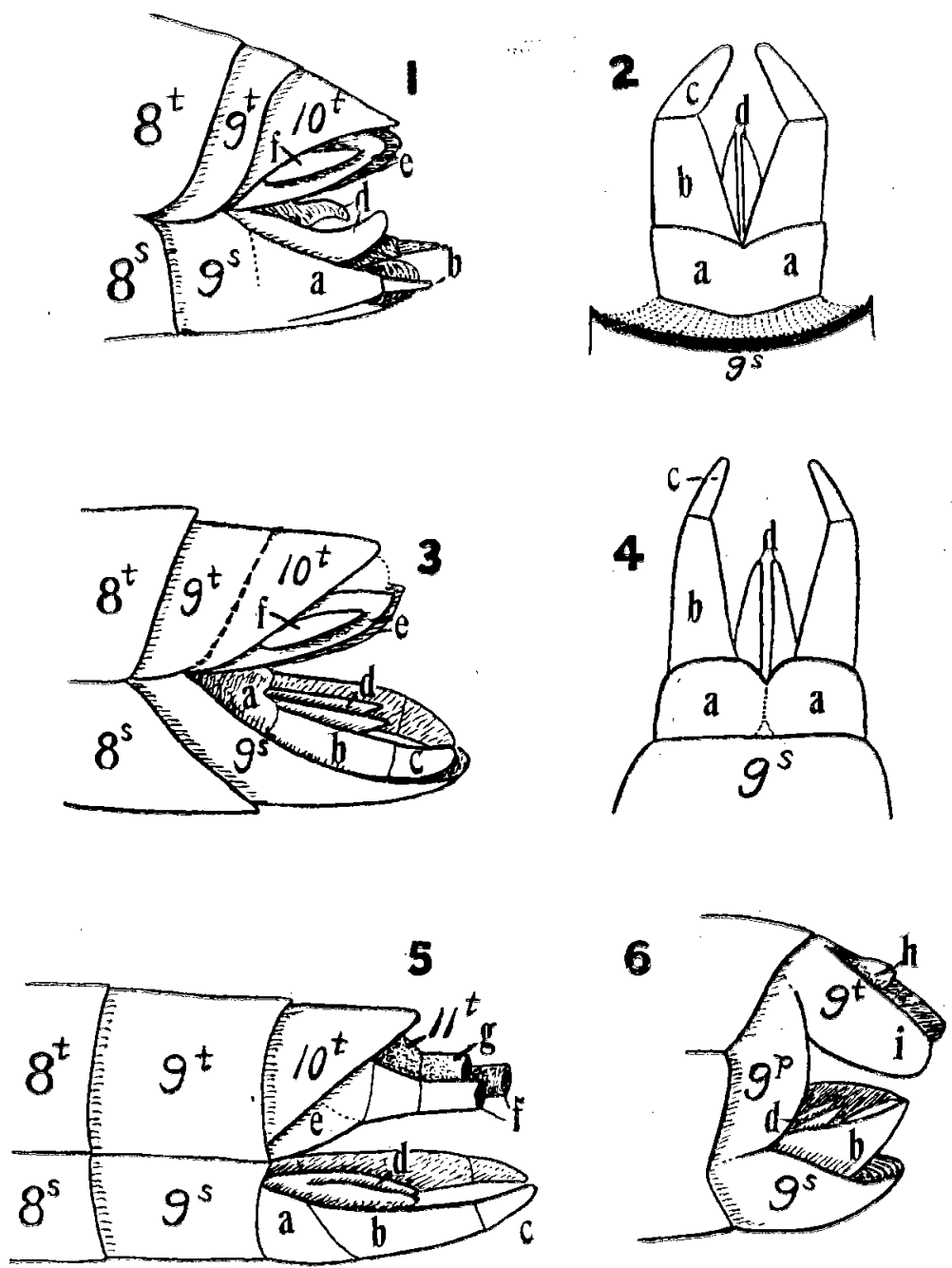

TERMINAL ABDOMIN $\Lambda$ I, STRUCTURES OF MALE INSECTS. (P. 183)

ward under the structures labeled "a," "b," "c," and "d" in Fig. 5, thus bringing them into the position of the structures labeled "a," "b," "c," and "d" in Fig. 3. If the plate bearing the labels "a" and "a" in Fig. 2 of a sawfly, represents the plate labeled "a" and "a" in Fig. 4 of an ephemerid, it is quite evident that the styligers or "coxites" whose fusion product is represented by the plate bearing the labels "a" and "a" in Fig. 2, are distinctly separated from the ninth sternite " 9 s" which originally bore them (?) thus presenting a condition comparable to 
that occursing in the male of Grylloblatk campodeiformis, which Walker, 1919 $(1, c)$ considered to be unique among winged insects.

The relative positions of the parts in the sawfly (Figs. 3 and 2 ) are essentially the same as in the more primitive representatives of the higher orders of insects, such as the tipulids among the Diptera, Philopotamus among the Trichoptera etc., but other structure become sccondarily developed in certain of these forms, thercby rendering the arrangement of the parts much more complicated and difficult of interpretation. As was described in a paper on the genitalia of male sawflies (Proc. Ent. Soc. Washington, 1919, Vol. 21, p. 129) there become differentiated from the distal portion of the segment "b" (Fig. 2) of the sawfly's gonopods, a pair of inner claspers which were interpreted as the volsellæ of higher Hymenoptera in the paper referred to above. These volsella-like structures probably correspond to the inner claspers of such Lepidoptera as the Geometrida, etc. One or both of the valves of the penis "d" may form a portion of the aedeagus; and numerous other changes take place through the outgrowth of various "prongs" and other structures, through the modification of the tergites, such as the posterior prolongations of the lateral region of the ninth tergite labeled " $i$ " in Fig. 6 , etc, but these features have been more fully described in an arlicle which will soon appear in Psyche, and need not be further discusscd here.

\section{ABBREVIATTONS.}

a. Styligers or "coxites"; basal structures bearing the styli. They may unite to"form a single plate or basal ring.

b. Basal segments of the styli or gonopods.

c. Distal segments of the styli or gonopods.

d. Penisvalve or valves of the "penis."

e. Paraprocts, or plates on either side of the anus.

f. Cerci.

g. Telofilum, or tcrminal filament.

h. Proctiger, or anal papilla bearing anus.

i. Surgonopods, or accessory claspers; prolongations of the ninth tergite.

The ninth sternite " $g$ ", forms the hypandrium, the ninth pleurite " $g$ ", forms the gonopleurite, and the tenth or eleventh tergite forms the epiproct. The letters $t, p$ and $s$ written to the right and above the numerals are used to indicate the tergite, pleurite and sternite of their respective scgments.

\section{EXPLANATION OF PLATE VI.}

Fig. 1. Lateral view of terminal structures of a blattid (based on Cryptocercus).

Fif. 2. Ventral view of genital forceps of a sawfly (based on Sirex).

Fig. 3. Lateral view of terminal structures of a sawfly.

Fig. 4. Ventral view of genital [orceps of a mayfly (based on Blasturus).

Fig. 5. Lateral view of terminal structures of a mayfly.

Fig. 9. Lateral view of terminal structures of a Neuropteron (based on Nymphes and Ithone).

All figures are very diagrammatic. 